\title{
Interleukin-31 promotes helper T cell type-2 inflammation in children with allergic rhinitis
}

\author{
Wenlong Liu', Renzhong Luo', Yanqiu Chen', Changzhi Sun', Jie Wang', Lifeng Zhou', Yan Li' and Li Deng'
}

BACKGROUND: Interleukin-31 (IL-31) is a recently described cytokine that is involved in helper T cell type-2 (Th2)-mediated diseases. However, its regulatory effect in the pathogenesis of children allergic rhinitis (AR) needs to be further characterized. This study sought to evaluate the expression and role of IL-31 in children with AR.

METHODS: Sixty children with AR and 20 normal controls were included. IL-31 and Th2 cytokines production in tissue, serum, and nasal lavage was examined by immunohistochemistry, quantitative polymerase chain reaction (qPCR), and enzyme-linked immunosorbent assay, respectively. Peripheral blood mononuclear cells (PBMCs) were purified for in vitro regulation experiment of IL-31. Nasal epithelial cells (NECs) were cultured and stimulated by recombinant IL-31.

RESULTS: The IL-31 mRNA and protein levels in both serum and nasal lavage were significantly enhanced in AR compared with normal controls, especially in children with asthma. The nasal IL-31 was associated with enhanced local Th2 cytokines and mucin 5AC (MUC5AC) expression. In vitro study showed that IL-31 promotes Th2 cytokines expression and MUC5AC upregulation and thus amplified Th2 inflammation.

CONCLUSION: Our results demonstrate that IL-31 expression in AR aggravated and amplified Th2 inflammation as well as mucin production, and provide a possible explanation for IL-31's regulatory role in the pathogenesis of AR.

A llergic rhinitis (AR) is a common nasal disease and affects $10-40 \%$ of children with increasing prevalence $(1,2)$. AR frequently coexists with asthma (most studies report a rate of $50-60 \%$ ) in children (3). The major histological features of AR include helper T cell type-2 (Th2) inflammation accompanied by infiltration with eosinophils, allergen-specific IgE production, and thickening of the basement membrane (4,5). Activation of Th2 cells and further released cytokines induced accumulation of inflammatory cells, such as B cells, plasma cells, eosinophils, basophils, and neutrophils, which contributed to the occurrence of AR (6). Despite involvement of Th2 inflammation in AR was clearly clarified, its regulation was not fully understood.

Interleukin-31 (IL-31) is a newly discovered four-helix bundle cytokine and expressed by several types of cells under both normal and disease state, such as activated $\mathrm{CD} 4^{+} \mathrm{T}$ cells, mast cells, monocytes, macrophages, immature and mature monocyte-derived dendritic cells and so on (7). The receptor of IL-31 consists of IL-31 receptor A (IL-31RA) and the oncostatin M receptor that is constitutively expressed on epithelial cells (8). The role of IL-31 in allergic diseases mainly focused on atopic dermatitis. Stephan et al. reported elevated IL-31 expression in atopic dermatitis (9). UIrike et al. found a correlation of Th2 cytokines with increased level of IL-31 in children with extrinsic atopic dermatitis (10). However, studies on respiratory allergic diseases are relatively few. Recently, Lei et al. (11) reported that high IL-31 level in asthmatic subjects, suggesting that IL-31 may be a useful indicator of asthma. Moreover, IL-31 was found to be closely associated with IgE production in asthmatic patients (12). Besides, IL-31 may play an important role in mucus overproduction in AR (13).

Growing evidences suggest a positive role for IL-31 in Th2linked AR. Thus, our study was undertaken to determine the expression and role of IL-31 in children with AR accompanied with or without asthma.

\section{RESULTS}

\section{Demographic and Laboratory Characteristics of the Study Population}

This study was conducted with 80 children, 60 of whom suffered from $\mathrm{AR}$, with ages ranging between 19 and $185 \mathrm{mo}$ (mean age: $77.7 \pm 39.0 \mathrm{mo}, 28$ males), and 20 of whom were healthy controls with ages ranging between 15 and 182 mo (mean age: $73.0 \pm 36.8$ mo, 11 males). The demographic features and laboratory parameters of the population are presented in Table 1. Asthma was found to be $30 \%$ in the AR group. When the two groups were compared, the basophil count, the eosinophil count, total serum $\mathrm{IgE}$, and eosinophil cationic protein (ECP) levels were found to be higher in the AR group, than those of the control group, especially in children with asthma.

\section{Increased Serum and Local IL-31 mRNA and Protein Levels as Well as Th2 Cytokines Protein in AR}

The serum and local IL-31 mRNA and protein expression in AR were significantly higher than those in the normal controls, especially in those children with asthma $(P=0.001$, 
Figure 1a-d). We also compared IL-31 expression between AR children who are $>6 \mathrm{y}$ and $<6 \mathrm{y}$ and no differences were found (data not shown). Our results showed that enhanced protein expression of IL-4, IL-13, IL-5, IL-6, IL-8, and vascular endothelial growth factor (VEGF) in serum and nasal lavage of AR children compared with control ( $P=0.001$, Figure 2a-1), especially in children with asthma. High expression of mucin 5AC (MUC5AC) was only found in nasal lavage instead of serum in AR children, especially in those children with asthma $(P=0.001$,
Figure 2m). Nasal IL-4, IL-5, IL-13, and MUC5AC were positively correlated with local IL-31, respectively (Figure 3a-d). The serum ECP and IgE levels as well as eosinophil counts were found positively correlated with serum IL-31 expression $(P<0.001$, Figure $3 \mathrm{e}-\mathrm{g})$. Besides, serum VEGF expression was positively correlated with IL-31 expression in asthma children $(P<0.001$, Figure 3h). The serum IL-6, IL-8, and VEGF expression was positively correlated with neutrophil counts in asthma children $(P<0.001$, Figure $3 \mathbf{i}-\mathbf{k})$.

Table 1. Demographic characteristics of AR children and normal controls

\begin{tabular}{|c|c|c|c|}
\hline Group & AR group & AR with asthma group & Control \\
\hline Number & 42 & 18 & 20 \\
\hline Sex (male:female) & $22: 20$ & $10: 8$ & $12: 8$ \\
\hline History of asthma, $n(\%)$ & - & $18(100)$ & - \\
\hline Family history of atopy, $n$ (\%) & $20(47.6)^{*}$ & $10(55.5)^{*}$ & $2(10)$ \\
\hline Neutrophils ${ }^{\mathrm{a}}$ (count/mm³) & $8,700(3,000-15,300)$ & $11,400(8,000-18,600)^{*},{ }^{* *}$ & $7,700(3,300-12,900)$ \\
\hline Basophils ${ }^{\mathrm{a}}$ (count/mm³) & $40(10-140)^{*}$ & $38(5-120)^{*}$ & $10(3-15)$ \\
\hline Monocytes ${ }^{\mathrm{a}}$ (count $/ \mathrm{mm}^{3}$ ) & $256(70-2,740)$ & $289(80-2,660)$ & $242(80-2,480)$ \\
\hline Lymphocytes ${ }^{\mathrm{a}}$ (count/mm³) & $6,900(3,100-16,400)$ & $7,600(2,900-17,100)$ & $8,100(2,000-14,300)$ \\
\hline
\end{tabular}

AR, allergic rhinitis; ECP, eosinophil cationic protein; IgE, immunoglobulin E.

a Data presented as median values (minimum-maximum). * Compared with control group, $P<0.05 .{ }^{*}$ Compared with AR group, $P<0.05$.
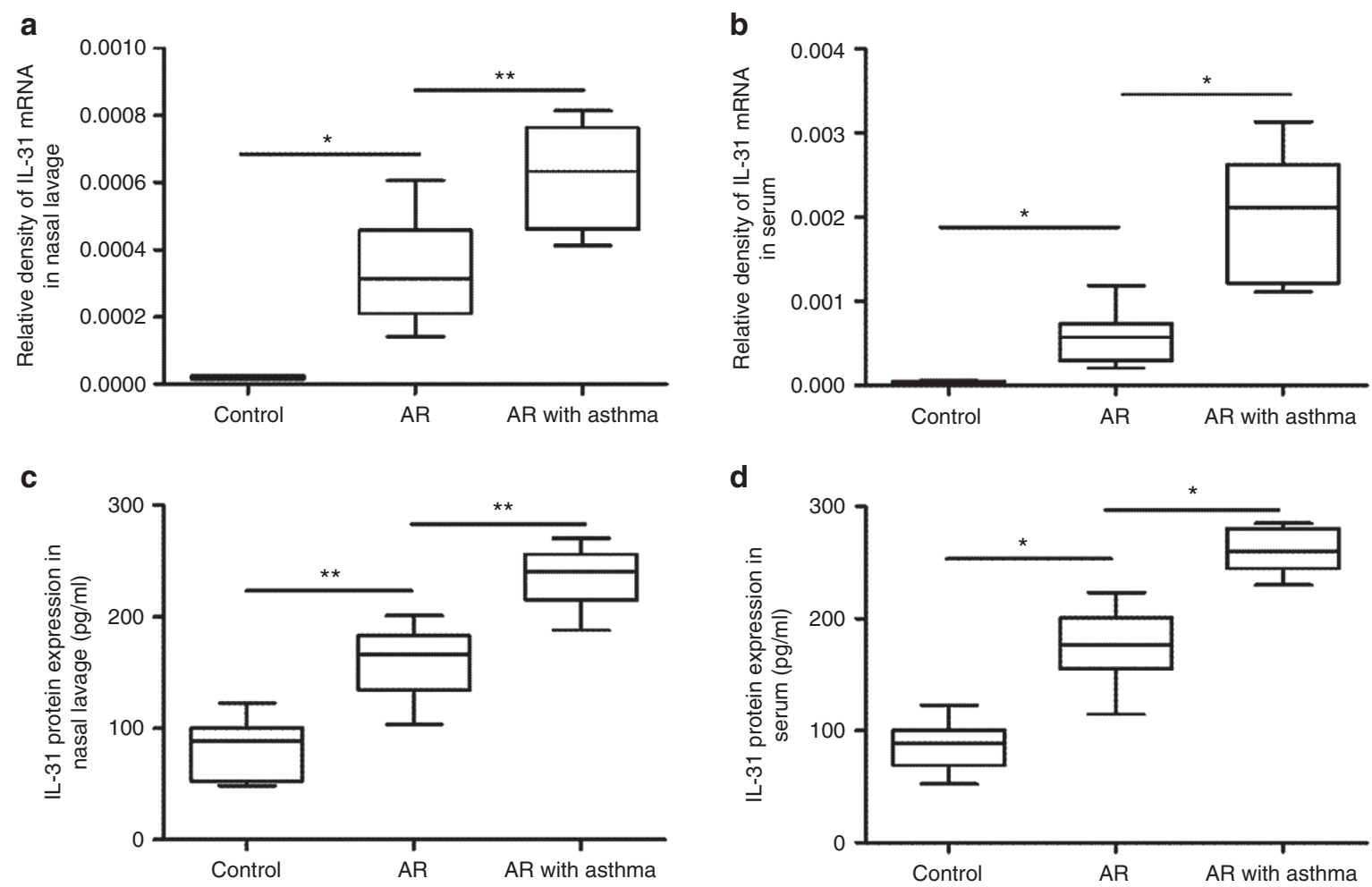

Figure 1. Serum and nasal interleukin (IL)-31 mRNA and protein expression levels in allergic rhinitis (AR) were significantly higher than those in the normal controls, especially in those patients with asthma (a-d). (a) ${ }^{*} P<0.01$, Con vs. AR; ${ }^{* *} P<0.05$, AR vs. AR with asthma. (b) ${ }^{*} P<0.01$, Con vs. AR; ${ }^{*} P<0.01$, AR vs. AR with asthma. (c) ${ }^{* *} P<0.05$, Con vs. AR; ${ }^{* *} P<0.05$, AR vs. AR with asthma. (d) ${ }^{*} P<0.01$, Con vs. AR; ${ }^{*} P<0.01, A R$ vs. AR with asthma. 


\section{Articles | Liu et al.}

$\mathbf{a}$

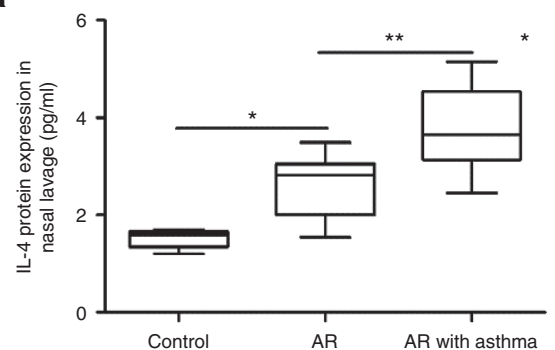

d

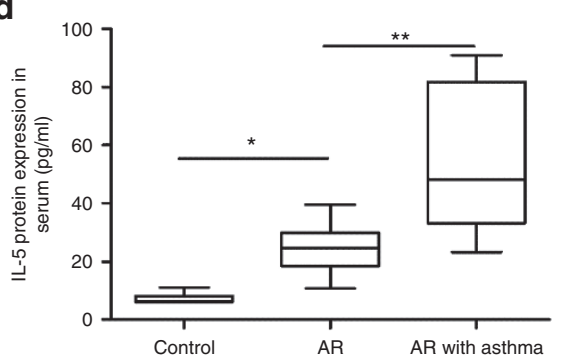

g

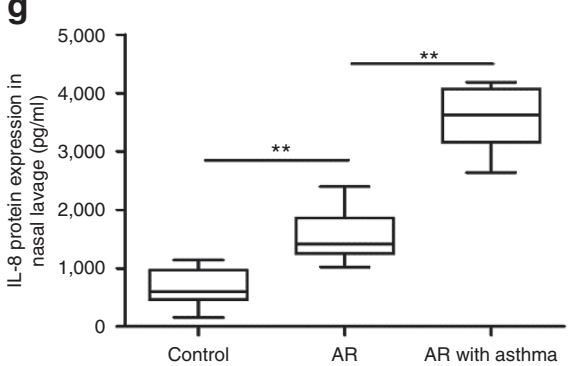

j
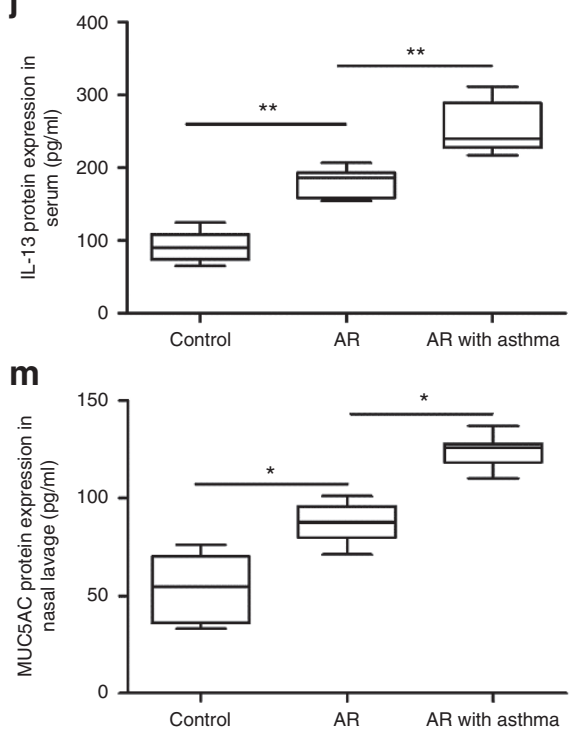

b

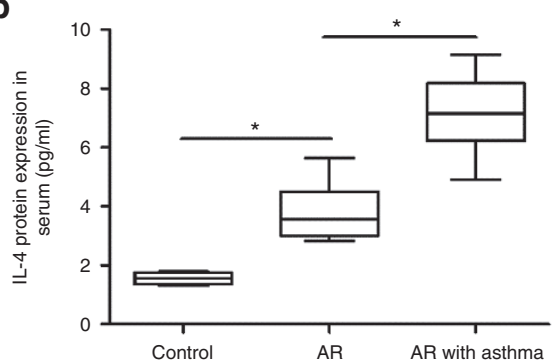

e

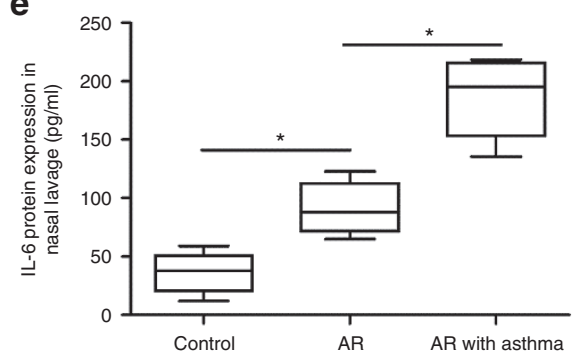

h

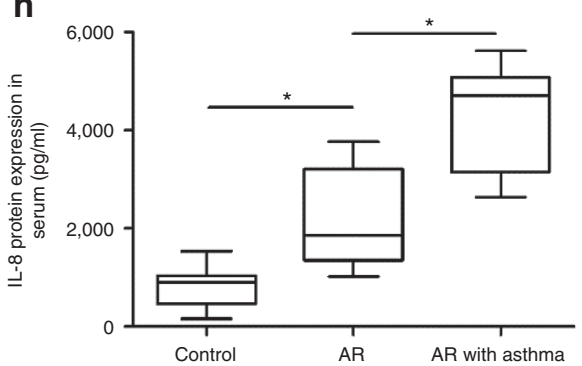

k

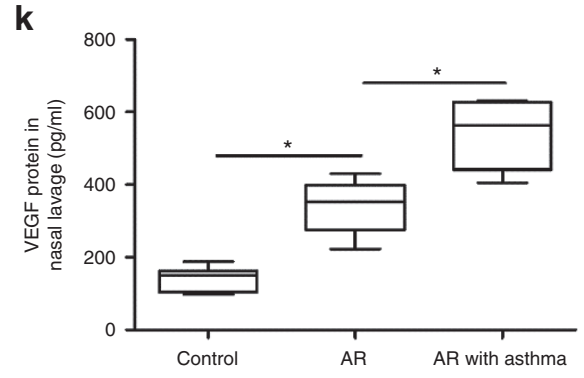

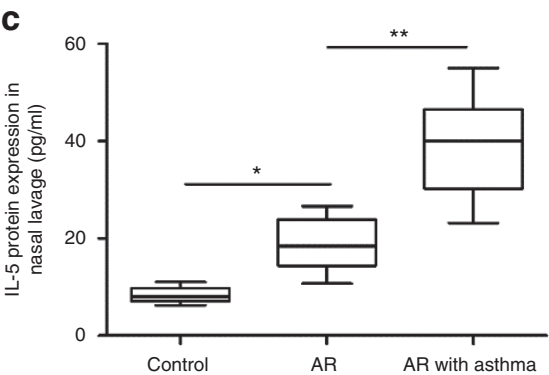

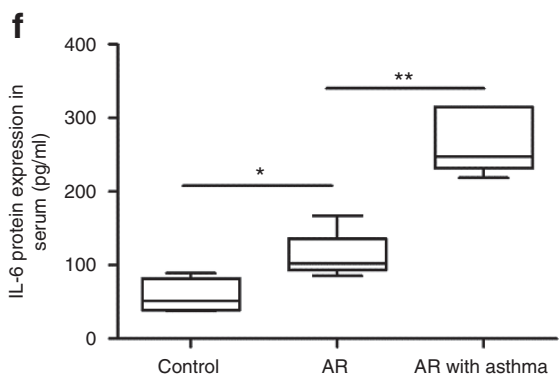

i

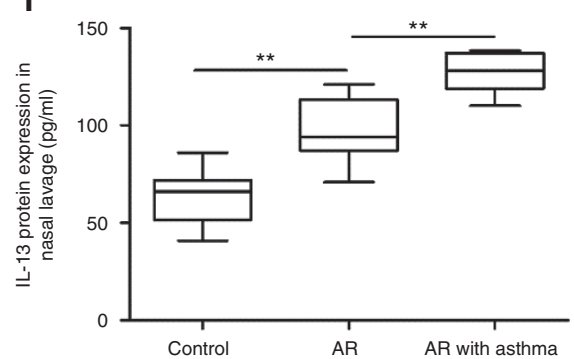

I

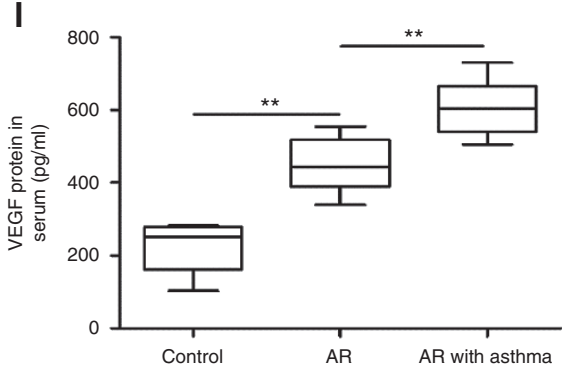

Figure 2. Serum and nasal interleukin (IL)-4, IL-5, IL-6, IL-8, IL-13, vascular endothelial growth factor (VEGF) protein, and nasal MUC5AC levels in allergic rhinitis (AR) were significantly higher than those in the normal controls, especially in those patients with asthma (a-m). (a,c,d,f) ${ }^{*} P<0.01$, Con vs. AR; ${ }^{* *} P<0.05$, AR vs. AR with asthma. (b,e, h, $\left.\mathbf{k}, \mathbf{m}\right){ }^{*} P<0.01$, Con vs. AR; ${ }^{*} P<0.01, A R$ vs. AR with asthma. (g,i,j, $\left.\mathbf{l}\right){ }^{* *} P<0.05$, Con vs. AR; ${ }^{* *} P<$ 0.05, AR vs. AR with asthma.

Increased IL-31 and Th2 Cytokine Expression in AR Tissues

In AR tissues, the number of IL-31-positive cells per high power field $(\times 200)$ was significantly higher than that of normal controls (Figure 4a), especially in children with asthma.
Similarly, IL-4, IL-5, and IL-13 protein were also highly expressed by AR tissues (Table 2). The positive relationship between number of IL-31-positive cells and Th2 cytokines were also found (Figure $4 \mathrm{~b}-\mathrm{d}$ ). 
a

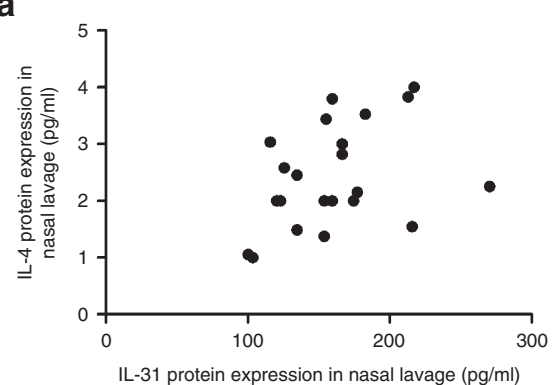

d

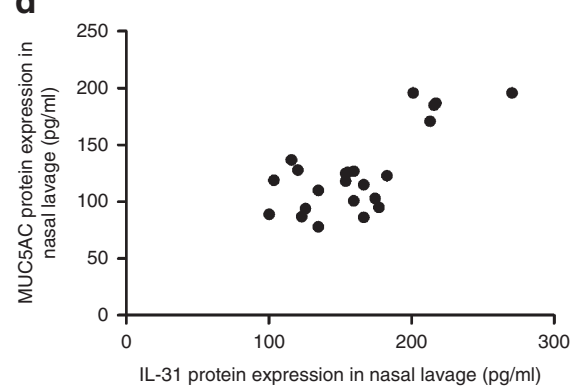

$\mathbf{g}$
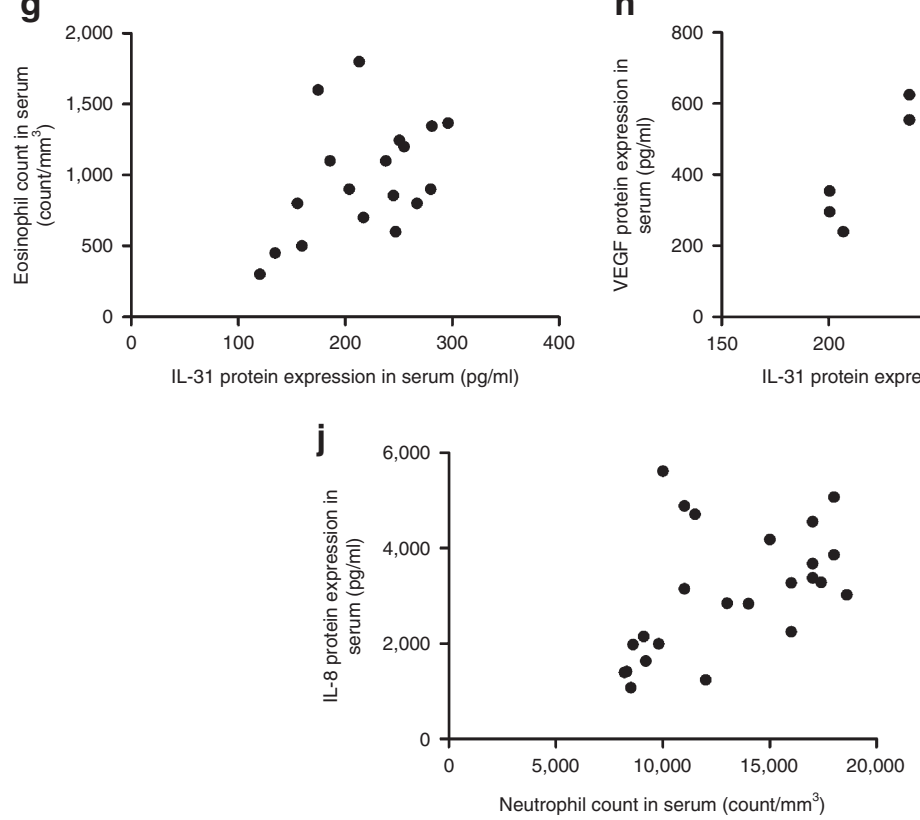

b

e

h
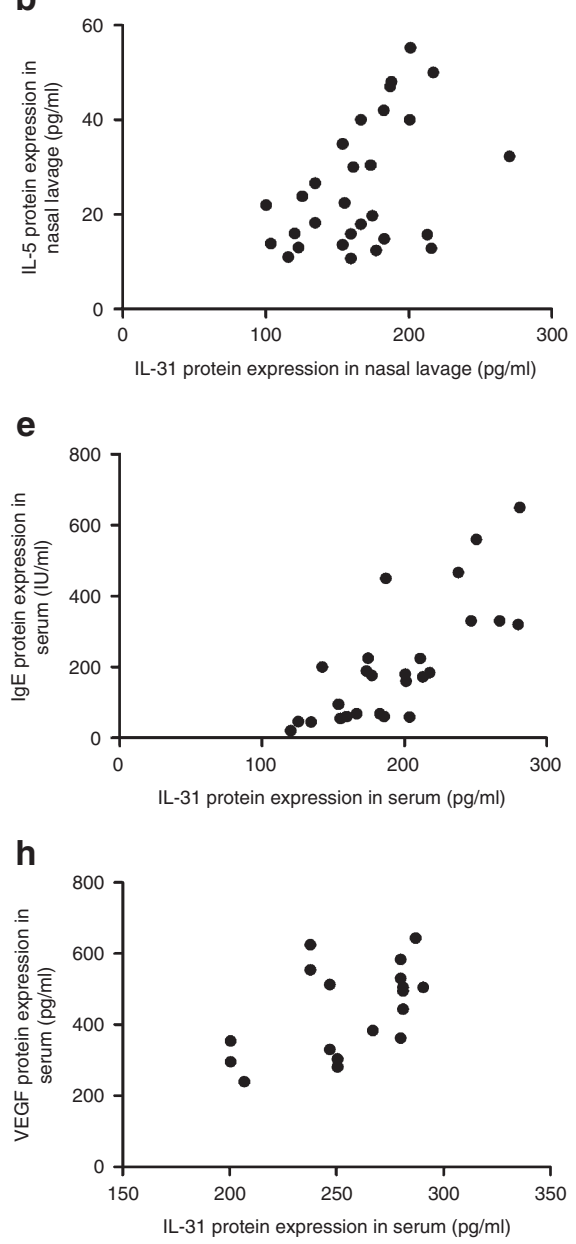

k

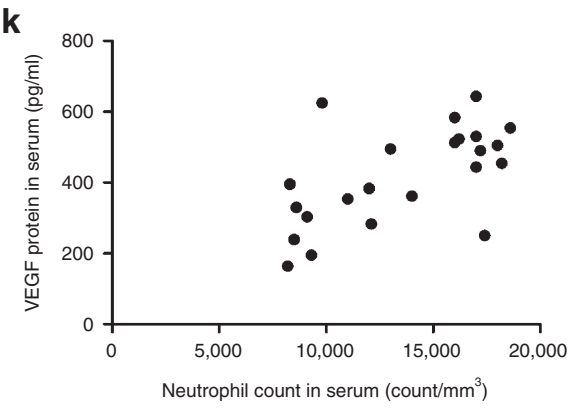

Figure 3. The protein levels of nasal interleukin (IL)-31 were positively correlated with nasal IL-4, IL-5, IL-13, MUC5AC, IgE, and eosinophil cationic protein levels (a-f). (a) $r=0.47, P=0.02 ;(\mathbf{b}) r=0.41, P=0.01$; (c) $r=0.53, P=0.01 ;$ (d) $r=0.48, P=0.02 ;$ (e) $r=0.74, P=0.01$; (f) $r=0.73, P=0.01$. The protein levels of serum IL-31 were positively correlated serum eosinophil count and vascular endothelial growth factor (VEGF) levels $(\mathbf{g}, \mathbf{h})$. (g) $r=$ $0.47, P=0.04$; (h) $r=0.53, P=0.02$. The neutrophil count in serum was positively correlated with serum IL-6, IL-8, and VEGF protein levels (i-k). (i) $r=$ $0.88, P=0.01 ;(\mathbf{j}) r=0.49, P=0.01 ;(\mathbf{k}) r=0.6, P=0.01$.

\section{IL-31 Promotes Th2 Inflammation of Peripheral Blood Mononuclear Cells (PBMCs)}

After stimulated with rhIL-31 or poly I:C, we found significant upregulation of Th2 cytokines (IL-4, IL-5, IL-13) level in PBMCs from $A R$ donor in a dose-dependent manner (Figure 5a-c). In PBMCs from controls, these changes were not found. Interestingly, when we used combination of IL-31 and IL-4/ IL-5/IL-13 to stimulate PBMCs, the Th2 cytokine production was more obvious compared with stimulation by single IL-31
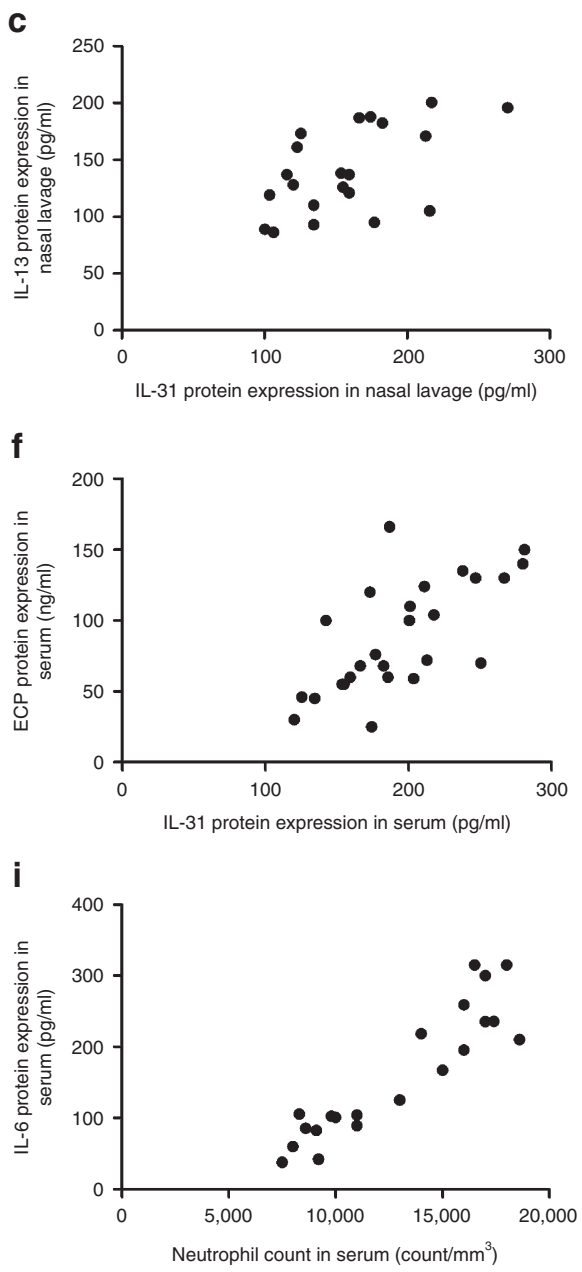

levels (i-k). (i) $r=$
.73, $P=0.01$. The
ls (g,h). (g) $r=$
lick
(Figure 5a-c). However, anti-IL-31 can block poly I:C induced Th 2 cytokines production, which further confirmed the positive role of IL-31 on Th2 cells (Figure 5a-c). To investigate the effect of Th2 cytokines on IL-31 expression, we used rhIL-4/IL-5/IL-13 to stimulated PBMCs and found no changes of IL-31 expression (data not shown), suggesting that involvement of IL-31 in AR occurrence was a single-way manner. We also detected the IL-12 and IFN- $\gamma$ after IL-31 stimulation and found no changes of these cytokines (data not shown). 
a

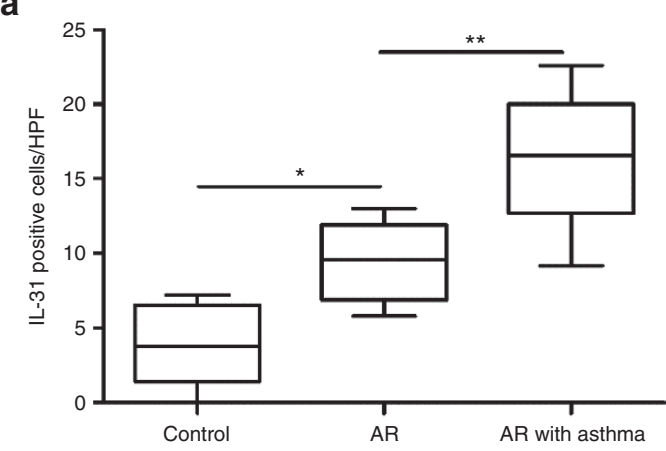

C

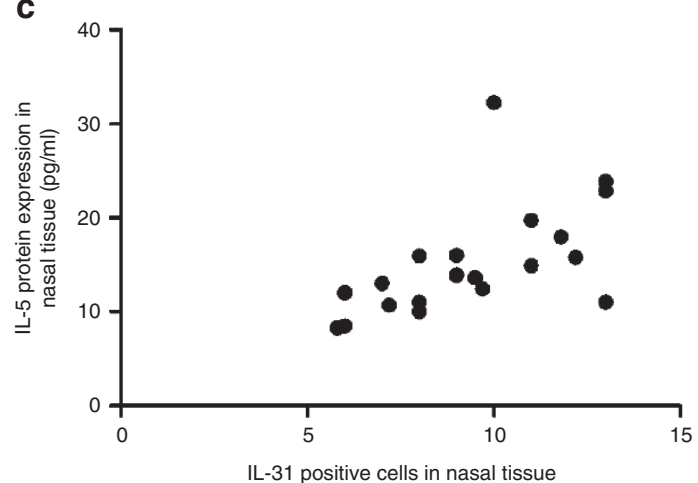

b

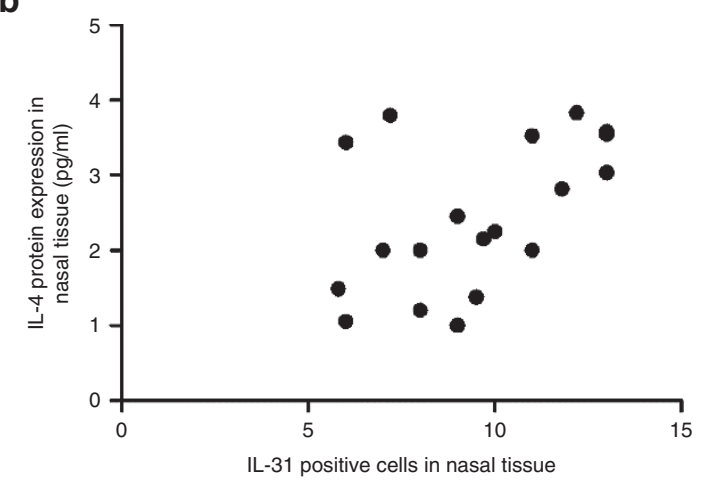

d

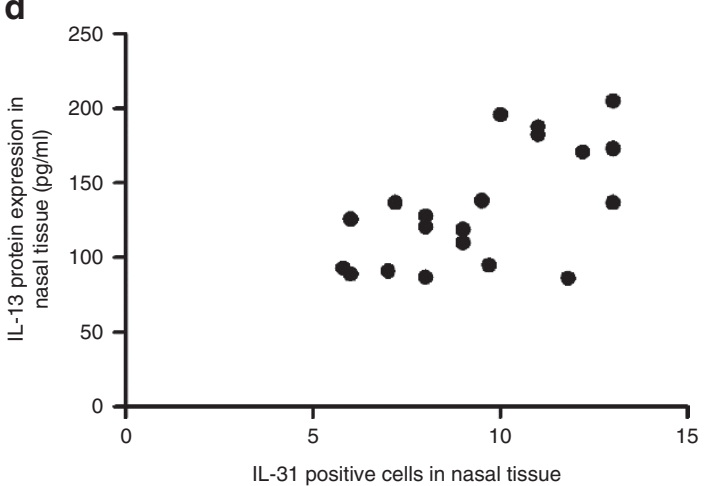

Figure 4. The number of IL-31-positive cells per high-power field $(\times 200)$ was significantly higher than that of normal controls, especially in children with asthma (a, ${ }^{*} P<0.01$, Con vs. allergic rhinitis (AR); ${ }^{* *} P<0.05$, AR vs. AR with asthma). The positive relationship between number of IL-31-positive cells and Th2 cytokines (IL-4, IL-5, IL-13) was also found (Figure 4, b-d). (b) $r=0.61, P=0.02 ;$ (c) $r=0.73, P=0.01 ;(\mathbf{d}) r=0.68, P=0.02$.

Table 2. Th2 cytokine protein expression in $60 \mathrm{AR}$ children and 20 normal controls

\begin{tabular}{lccc}
\hline & $\begin{array}{c}\text { AR group } \\
(42 \text { cases })\end{array}$ & $\begin{array}{c}\text { AR with asthma } \\
\text { group (18 cases) }\end{array}$ & $\begin{array}{c}\text { Controls } \\
\text { (20 cases) }\end{array}$ \\
\hline $\mathrm{IL}-4(\mathrm{pg} / \mathrm{ml})$ & $2.57 \pm 0.66^{*}$ & $3.79 \pm 0.87^{* * *}$ & $1.59 \pm 0.19$ \\
$\mathrm{IL}-5(\mathrm{pg} / \mathrm{ml})$ & $18.82 \pm 4.3^{*}$ & $39.64 \pm 9.2^{*},{ }^{* *}$ & $8.49 \pm 1.67$ \\
$\mathrm{IL}-13(\mathrm{pg} / \mathrm{ml})$ & $97.06 \pm 16.3^{*}$ & $127.9 \pm 10.6^{*},{ }^{* *}$ & $63.52 \pm 14.88$ \\
\hline
\end{tabular}

AR, allergic rhinitis.

*Compared with control group, $P<0.05 .{ }^{* *}$ Compared with AR group, $P<0.05$.

\section{IL-31 Induces Upregulation of Th2 Cytokines and ECP as Well as MUC5AC Production in Nasal Epithelial Cells (NECs)}

After stimulated with various concentrations of IL-31 (1$100 \mathrm{ng} / \mathrm{ml}$ ) with or without rhIL-17 and rhIL-4, we found significant upregulation of Th2 cytokines (IL-4, IL-5, IL-13) and ECP as well as MUC5AC production in NECs (Figure 6a-e) and Th1 cytokines (IL-12 and IFN- $\gamma$ ) changes were not observed, confirming the positive regulation of IL-31 in Th2 inflammation development. We also found that IL-31 can promote ECP production, suggesting its role in eosinophil activation. On the contrary, rhIFN- $\gamma$ did not affect IL-31-mediated upregulation of Th2 cytokines and ECP as well as MUC5AC.

\section{DISCUSSION}

Our present study demonstrates for the first time that elevated IL-31 expression in AR was closely related to the development of Th2 inflammation. In vitro study also revealed direct stimulation of IL-31 on PBMCs and NECs. Besides, IL-31 is also involved in MUC5AC and VEGF production. Therefore, our study may deepen our knowledge on the pathogenesis and molecular mechanism of AR.

IL-31 as a multifunctional protein has been investigated in allergy and asthma until recently $(11,12)$. A number of studies have shown enhanced IL-31 expression by PBMCs and local nasal mucosa in AR and asthma patient $(14,15)$. However, the regulation and expression in AR children was not known. Our study showed the mean number of IL-31-positive cells and Th2 cytokines was significantly increased in AR turbinate tissue. The relationship between Th2 cytokines (IL-4, IL-5, IL-13) and IL-31 expression was found only in nasal lavage and turbinate tissue instead of serum, suggesting that IL-31 promotes Th2 inflammation locally rather than systematically, despite Th2 cytokines expression was enhanced in both serum and nasal lavage.

The eosinophil infiltration, release of ECP, and IgE production were important features of AR (16). Thus, we detected eosinophil counts and examined IgE and ECP expression and their relation with IL-31. As we expected, eosinophil counts, total $\operatorname{IgE}$ and ECP in serum were positively related to serum IL-31 expression, suggesting IL-31-mediated production of IgE and ECP by eosinophils and B cells. As hypersecrtion is a major symptom of AR, we detected MUC5AC expression and found that IL-31 can induce local mucin production directly, which was consistent with previous reports (13). 
a

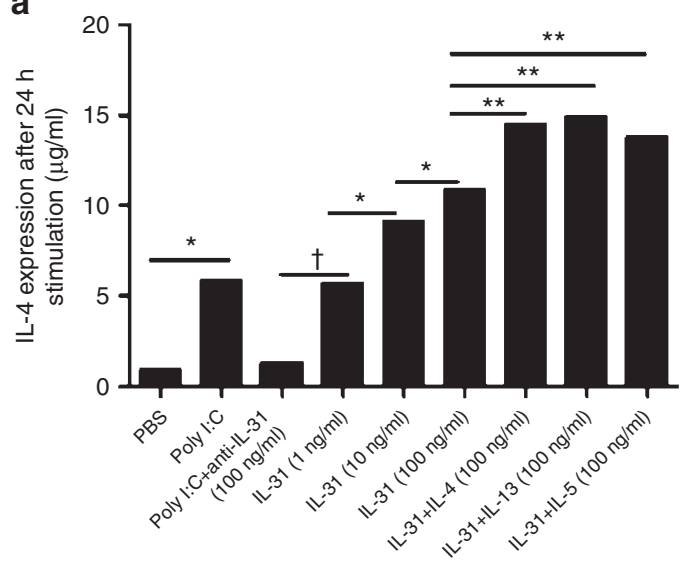

b

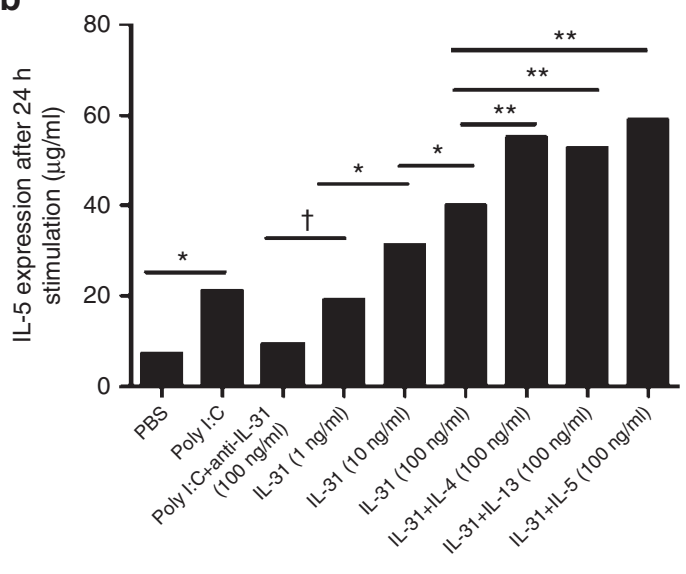

C

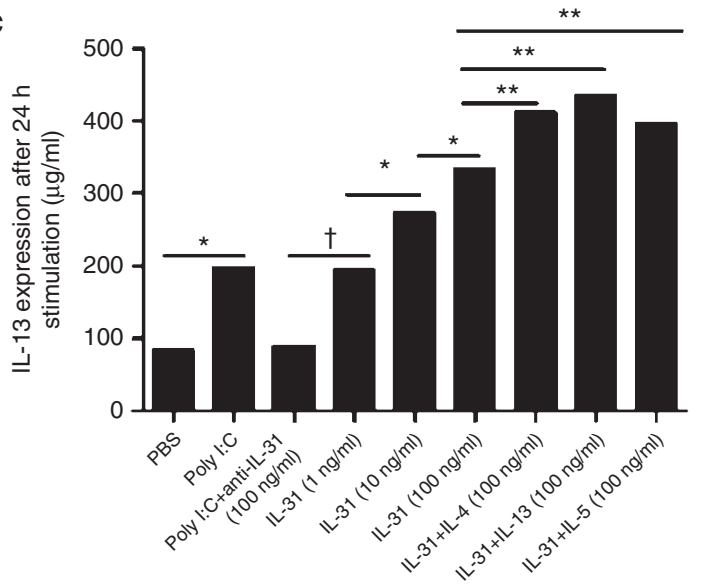

Figure 5. After stimulation with rhIL-31, significant upregulation of Th2 cytokine (IL-4, IL-5, IL-13) levels in peripheral blood mononuclear cells (PBMCs) from AR donor occurred in a dose-dependent manner, especially when we used combination of IL-31 and IL-4/IL-5/IL-13 to stimulate PBMCs. Anti-IL-31 can block poly I:C induced Th2 cytokine production. (a) ${ }^{*} P<0.01, \mathrm{PBS}$ vs. Poly I:C, IL-31 (10 ng/ml) vs. IL-31 (1 ng/ml), IL-31(10 ng/ml) vs. IL-31

$(100 \mathrm{ng} / \mathrm{ml}) ;{ }^{* *} P<0.05, \mathrm{IL}-31(100 \mathrm{ng} / \mathrm{ml}) \mathrm{vs}$. IL-31+IL-4 (100 ng/ml), IL-31 (100 ng/ml) vs. IL-31+IL-5 (100 ng/ml), IL-31 (100 ng/ml) vs. IL-31+IL-13 $(100 \mathrm{ng} / \mathrm{ml}) ;{ }^{\dagger} P<0.001, \mathrm{IL}-31(1 \mathrm{ng} / \mathrm{ml})$ vs. Poly l:C+anti-IL-31 $(100 \mathrm{ng} / \mathrm{ml}) .(\mathbf{b}){ }^{*} P<0.01, \mathrm{PBS} \mathrm{vs}$. Poly l:C, IL-31 (10 ng/ml) vs. IL-31 (1 ng/ml), IL-31 (10 ng/ml) vs. IL-31 (100 ng/ml); ${ }^{* * P}<0.05, \mathrm{IL}-31(100 \mathrm{ng} / \mathrm{ml}) \mathrm{vs}$. IL-31+IL-4 (100 ng/ml), IL-31 (100 ng/ml) vs. IL-31+IL-5 (100 ng/ml), IL-31 (100 ng/ml) vs. IL-31+IL-13 $(100 \mathrm{ng} / \mathrm{ml}) ;{ }^{\dagger} P<0.001, \mathrm{IL}-31$ (1 ng/ml) vs. Poly I:C+anti-IL-31 (100 ng/ml). (c) ${ }^{*} P<0.01, \mathrm{PBS}$ vs. Poly I:C, IL-31 (10 ng/ml) vs. IL-31 (1 ng/ml), IL-31 (10 ng/ml) vs. IL-31 (100 ng/ml); ${ }^{*} P<0.05$, IL-31 (100 ng/ml) vs. IL-31+IL-4 (100 ng/ml), IL-31 (100 ng/ml) vs. IL-31+IL-5 (100 ng/ml), IL-31 (100 ng/ml) vs. IL-31+IL-13 (100 ng/ml); ${ }^{\dagger} P<0.001, \mathrm{IL}-31(1 \mathrm{ng} / \mathrm{ml})$ vs. Poly I:C+anti-IL-31 (100 ng/ml).

Interestingly, we found that high expression of IL-31 was more obvious in AR children with concomitant asthma. Neutrophil infiltration and neoangiogenesis were related with severity of asthma (17). IL-8 is a potent neutrophil chemoattractant and activator of neutrophils and is produced by a number of airway inflammatory cells, including neutrophils (18). Besides, IL-6 plays important role in asthma, especially in neutrophil infiltration (19). VEGF, previously known as vascular permeability factor, is the most specific growth factor for vascular endothelium (20). Our results showed that neutrophil count was positively correlated with serum IL-6 and IL-8 level, suggesting that these cytokines were involved in infiltration of neutrophils. However, no relation between IL-31 and neutrophil count or IL-6/IL-8 was found (data not shown). These results provide evidence that neutrophil inflammation in asthma was not regulated by IL-31. We also found that serum VEGF was related to both neutrophil count and serum IL-31 expression. Consistent with our results, Ip's recent study had shown that IL-31 could significantly increase gene and protein expression of epidermal growth factor, VEGF, and monocyte chemoattractant protein-1 (MCP-1/CCL2) in human bronchial epithelial cells (BEAS-2B cells) both in a time and dose-dependent manner (21). In a recent study by Gong (22), neutrophils may exercise their angiogenic function by releasing proangiogenic factors such as VEGF, which may be the explanation for relationship between VEGF and neutrophil count in our study.

To characterize IL-31's direct role in AR, we purified PBMCs from both AR and control donors. Our results showed that IL-31 induced significant upregulation of Th2 cytokines level in PBMCs from AR donor in a dose-dependent manner (no differences were found in children with and without asthma). To investigate the effect of Th2 cytokines on IL-31 expression, we further used rhIL-4/IL-5/IL-13 to stimulated PBMCs and found no changes of IL-31 expression. Interestingly, when we used combination of IL-31 and IL-4/IL-5/IL-13 to stimulate PBMCs, the Th2 cytokine production was more obvious compared with single IL-31. However, block of IL-31 can reduce 

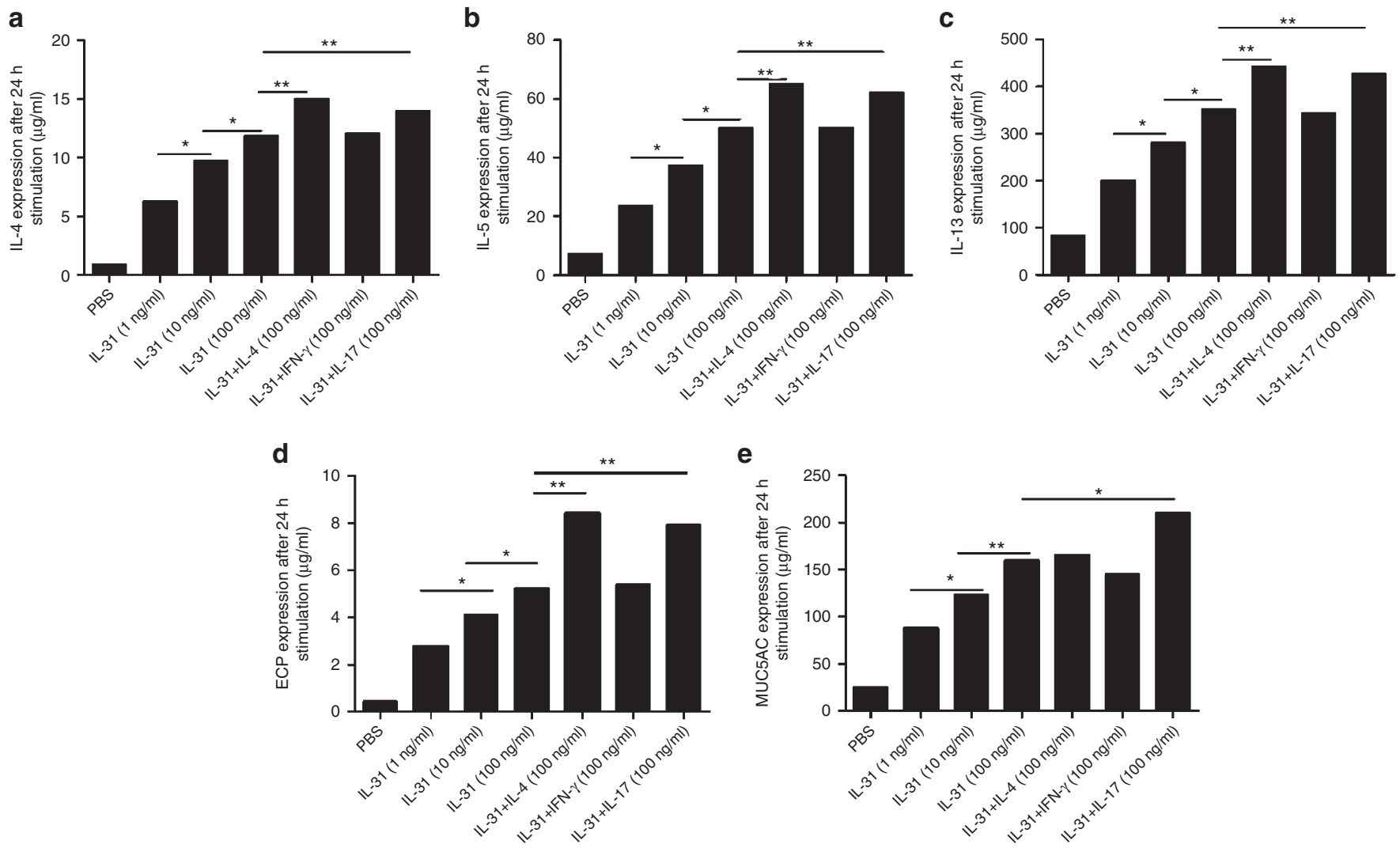

Figure 6. After stimulation with various concentrations of interleukin (IL)-31 (1-100 ng/ml) with or without rhIL-17, rhIFN- $\gamma$, rhIL-4, there was significant upregulation of Th2 cytokine (IL-4, IL-5, IL-13) and eosinophil cationic protein as well as MUC5AC production in nasal epithelial cells (a-e). (a) $* P<0.01$, IL-31 $(10 \mathrm{ng} / \mathrm{ml})$ vs. IL-31 $(1 \mathrm{ng} / \mathrm{ml})$, IL-31 $(10 \mathrm{ng} / \mathrm{ml})$ vs. IL-31 $(100 \mathrm{ng} / \mathrm{ml}) ; * * P<0.05$, IL-31 $(100 \mathrm{ng} / \mathrm{ml}) \mathrm{vs}$. IL-31+IL-4 $(100 \mathrm{ng} / \mathrm{ml})$, IL-31 $(100 \mathrm{ng} / \mathrm{ml})$ vs. IL-31+IL-17 (100 ng/ml). (b) *P< 0.01, IL-31 (10 ng/ml) vs. IL-31 (1 ng/ml), IL-31 (10 ng/ml) vs. IL-31 (100 ng/ml); ** $<0.05$, IL-31 (100 ng/ml) vs. IL-31+IL-4 $(100 \mathrm{ng} / \mathrm{ml}), \mathrm{IL}-31(100 \mathrm{ng} / \mathrm{ml}) \mathrm{vs}$. IL-31+IL-17 $(100 \mathrm{ng} / \mathrm{ml}) .(\mathrm{c}){ }^{*} P<0.01, \mathrm{IL}-31(10 \mathrm{ng} / \mathrm{ml}) \mathrm{vs}$. IL-31 $(1 \mathrm{ng} / \mathrm{ml}), \mathrm{IL}-31(10 \mathrm{ng} / \mathrm{ml}) \mathrm{vs}$. IL-31 $(100 \mathrm{ng} / \mathrm{ml}) ; * * P<0.05$, IL-31 $(100 \mathrm{ng} / \mathrm{ml})$ vs. IL-31+IL-4 $(100 \mathrm{ng} / \mathrm{ml}), \mathrm{IL}-31(100 \mathrm{ng} / \mathrm{ml}) \mathrm{vs.} \mathrm{IL-31+IL-17}(100 \mathrm{ng} / \mathrm{ml}) .(\mathbf{d}) * P<0.01, \mathrm{IL}-31(10 \mathrm{ng} / \mathrm{ml}) \mathrm{vs} . \mathrm{IL}-31(1 \mathrm{ng} / \mathrm{ml}), \mathrm{IL}-31(10 \mathrm{ng} / \mathrm{ml})$ vs. IL-31 (100 ng/ml); **P < 0.05, IL-31 (100 ng/ml) vs. IL-31+IL-4 (100 ng/ml), IL-31 (100 ng/ml) vs. IL-31+IL-17 (100 ng/ml). (e) ${ }^{*} P<0.01$, IL-31 (10 ng/ml) vs. IL-31 (1 ng/ml), IL-31 (100 ng/ml) vs. IL-31+IL-17 (100 ng/ml); **P<0.05, IL-31 $(10 \mathrm{ng} / \mathrm{ml}) \mathrm{vs.} \mathrm{IL-31}(100 \mathrm{ng} / \mathrm{ml})$.

poly I:C induced Th2 cytokines production, suggesting that IL-31 plays important roles in Th2 inflammation. These results suggested that involvement of IL-31 in AR occurrence was a single-way manner and IL-4/IL-5/IL-13 had an amplifying effect on Th2 cytokine production. However, in Bryony's study (15), they found that IL-4 had direct effect on IL-31 production by PBMCs, which may be attributed to different treatment methods. In their experiments, all PBMCs underwent 7 $\mathrm{d}$ stimulation with allergen. Besides, Kasraie's study found that IL-31-induced ERK 1/2 activation contributes to the underlying mechanism of Th1 cytokine IL-12 suppression in macrophages. IL-31 did not affect IL-12 expression in our study, which may be attributed to different cell types.

In our study, we also established NECs model to simulate the environment of AR. Our results showed that IL-31 can directly induce Th2 cytokine production and ECP by NECs and this effect was enhanced when IL-31 was combined with IL-4 or IL-17. These results suggested that IL-31 induced higher expression of Th2 cytokines and further combination with IL-31 and Th2 cytokines amplify the production of Th2 cytokines. This positive feedback promotes worsening of Th2 inflammation; finally, the occurrence of AR. IL-17A is a member of a novel family of proinflammatory cytokines, which has been found to be associated with a variety of inflammatory conditions in the lung, such as asthma, chronic obstructive pulmonary diseases, and bacterial pneumonia infection $(23,24)$. Recent studies using murine asthma models have shown that IL-17 receptor-deficient mice exhibit the reduced recruitment not only of neutrophils but also of eosinophils into the airways, resulting from the impaired priming of Th2 responses (25). IL-17A also induces MUC5AC and MUC5B production by primary normal human bronchial epithelial cells (26). Consistent with these reports, we found IL-17 can amplify IL-31-mediated Th2 inflammation and mucin production.

Collectively, our finding showed that IL-31 may be a critical cytokine, which mediates and amplifies Th2 inflammation as well as mucus production and a potential marker for predicting asthma in AR. Our research may provide a new target for AR prevention and treatment in future.

\section{METHODS}

\section{Patients}

Sixty children $(<18$ y old) with AR were recruited in the study. The diagnosis was established on history, clinical examination, skin prick test, and specific IgE measurement, which accorded with AR and its impact on asthma guideline (2010) (27). Of them, children with asthma were diagnosed according to the Global initiative for asthma 
criteria (28). Twenty children of similar age and gender with no history of allergic disease or wheezing were selected as the control group. Those with chronic diseases (e.g., malnutrition, anatomic malformation of the respiratory system, chronic lung disease, heart disease, gastro-oesophageal reflux disease, cystic fibrosis) and those with a history of chronic drug use (e.g., oral or nasal corticosteroids, antiepileptics, immune suppressives) were excluded from the study. The tissues from the inferior turbinate from nine AR children (12-17 y old) and eight controls (13-16 y old) underwent inferior turbinectomy due to severe nasal congestion were sampled for in vitro culture and immunohistochemistry test. This study was approved by the Guangzhou Women and Children's Medical Center Ethical Committee and informed consent was signed by the children's parents.

\section{Blood, Nasal Tissue, and Lavage Sample Preparation and Analysis}

Venous blood samples were collected into Vacuette tubes and centrifuged at $3,000 \mathrm{~g}$ for $15 \mathrm{~min}$ at $4^{\circ} \mathrm{C}$. Serum samples were stored at $-80^{\circ} \mathrm{C}$. These samples were used for enzyme-linked immunosorbent assay and quantitative polymerase chain reaction (qPCR) measurement. The whole blood cell counts were measured by LH-785 system (Beckman Coulter, Galway, Ireland). Total serum IgE was measured by electrochemiluminescence method using an ELX-800 system.

Hundred milligrams of freshly obtained tissue specimen were weighed, and $1 \mathrm{ml}$ protease inhibitor cocktail (Keygentec, Nanjing, China) was added per every $100 \mathrm{mg}$ tissue. The tissue was then homogenized with a homogenizer for $1 \mathrm{~min}$ on ice. After homogenization, the suspension was centrifuged at $4,000 \mathrm{rpm}$ for $20 \mathrm{~min}$ at $4{ }^{\circ} \mathrm{C}$, and the supernatants were stored at $-80^{\circ} \mathrm{C}$ until analyzed.

Nasal lavage was performed using saline warmed to $37^{\circ} \mathrm{C}$. The process was performed according to the method described elsewhere (29). Due to noncooperation of children, only 45 AR samples and 15 controls were collected. The samples were centrifuged to remove cellular debris, and aliquots of the supernatants were stored at $-20{ }^{\circ} \mathrm{C}$ in eppendorff tubes until analysis. Total protein concentrations were determined with Bio-Rad protein assays according to Bradford.

\section{Enzyme-Linked Immunosorbent Assay for Protein Expression and Electrochemiluminescence for ECP Protein Expression}

Enzyme-linked immunosorbent assay kits were used for measuring serum, nasal tissue and nasal lavage IL-31, IL-4, IL-13, IL-5, IL-6, IL-8, VEGF (R\&D systems, Minneapolis, MN), MUC5AC (Biocompare, San Francisco, CA), and ECP levels (EIAab, Wuhan, China), according to the manufacturer's protocols. The detection limits of the assays were as follows: IL-31, $125 \mathrm{pg} / \mathrm{ml}$; IL-4, $1.56 \mathrm{pg} / \mathrm{ml}$ IL-13, $93.8 \mathrm{pg} / \mathrm{ml}$; IL-5, $7.8 \mathrm{pg} / \mathrm{ml}$; IL-6, 0.7 pg/ml; IL-8, 7.5 pg/ml; MUC5AC, 78 pg/ml; VEGF, $9 \mathrm{pg} / \mathrm{ml}$.

\section{Real-Time PCR Analysis}

Real-time PCR was performed as we described previously (29). Total RNA was extracted from mucosa tissues using TRIzol reagent (Life Technologies, Carlsbad, CA) according to the manufacturer's instructions. Reverse transcription was performed, and cDNA was synthesized from $2 \mu \mathrm{g}$ of total RNA using an oligo (dT) 18 primer and M-MLV reverse transcriptase (Takara, Shiga, Japan). The mRNA expression was determined using an ABI PRISM 7300 Detection System (Applied Biosystems, Foster City, CA). The sequences of the primers were as follows: IL-31, forward primer: 5'-GTGCTCTTTCTGTTCTGCTG-3', reverse primer: $5^{\prime}$-CATTGATGGG TGTCTGTTGG-3'; $\beta$-actin, forward primer: 5'-AAG ATG ACC CAG ATC ATG TTT GAG ACC-3', reverse primer: 5'-AGC CAG GTC CAG ACG CAG GAT-3'; PRISM samples contained $1 \times$ SYBR Green Master Mix, $1.5 \mu \mathrm{l}$ of $5 \mu \mathrm{mol} / 1$ primers, and $25 \mathrm{ng}$ of synthesized cDNA in a 25 - $\mu$ l volume. Reactions were heated to $95^{\circ} \mathrm{C}$ for $10 \mathrm{~min}$, followed by 40 cycles of denaturation at $95^{\circ} \mathrm{C}$ for $10 \mathrm{~s}$, and annealing extension at $60^{\circ} \mathrm{C}$ for $60 \mathrm{~s}$. All PCR reactions were performed in duplicate. Melting curve analysis was used to control for amplification specificity. The mean value of the replicates for each sample was calculated and expressed as a cycle threshold $\left(C_{t}\right)$ value. The relative expression of each target gene was determined as the difference $\left(\Delta C_{t}\right)$ between the $C_{t}$ value of the target gene and the $C_{t}$ value of $\beta$-actin. Fold changes in the target gene mRNA were determined as $2^{-\Delta \Delta C t}$.

\section{Immunohistochemical Staining}

For immunohistochemistry, the slides were placed in $0.3 \% \mathrm{H}_{2} \mathrm{O}_{2}$ for $20 \mathrm{~min}$ at room temperature to reduce nonspecific background staining caused by endogenous peroxidase. After washing with phosphatebuffered saline (PBS) again, the slides were boiled in $10 \mathrm{mmol} / \mathrm{l}$ citrate buffer for $15 \mathrm{~min}$ followed by cooling at room temperature. Rabbit antihuman polyclonal antibody for IL-31 (LifeSpan Biosciences, Seattle, WA) and control antibody (Dako, Glostrup, Denmark) were incubated overnight at $4{ }^{\circ} \mathrm{C}$ for immunohistochemical staining, respectively. The next day, the slides were washed with PBS and incubated with secondary antibody (Gene Tech, Shanghai, China) at room temperature for $1 \mathrm{~h}$.

After washing, diaminobenzine (Gene Tech) staining was performed under microscope. After rinsing with distilled water, the sections were counterstained with Mayer's hematoxylin (Zhongshan Goldenbridge, Beijing, China) for a further $25 \mathrm{~s}$, dehydrated with series ethanol $(90 \%, 100 \%, 100 \%)$, cleared with xylene (three times), and mounted with neutral balsam (Zhongshan Goldenbridge). Control for nonspecific staining was routinely performed with PBS instead of primary antibodies and all proved negative.

The sections were blindly examined and coded with no awareness of the clinical data. They were visualized with an Olympus CX40 Microscope. In high-power fields $(\times 200)$, the count of IL-31-stained sections was performed. Ten fields were counted in each specimen and the median was calculated for each antibody.

\section{PBMC Preparation}

PBMCs were isolated by Lymphoprep (Fresenius Kabi Norge AS, Oslo, Norway) density-gradient centrifugation from heparinized leucocyte-enriched buffy coats, which were obtained from AR and control children. PBMCs were isolated by means of density gradient centrifugation and cultured at $2^{\star} 10^{6} / \mathrm{ml}$ in 24 -well plates in culture medium: RPMI 1640 supplemented with $5 \%$ human AB serum, $5 \mathrm{mmol} / \mathrm{l}$ glutamine, and penicillin and streptomycin solution. Stimulation was given through addition of rhIL-31, poly I:C with or without other cytokines or stimulators (rhIL-4, rhIL-5, rhIL-13).

\section{NEC Preparation}

NECs were prepared from inferior turbinate tissue by means of enzymatic digestion. Briefly, the minced tissues were incubated for $2 \mathrm{~h}$ at $37^{\circ} \mathrm{C}$ in RPMI 1640 containing $2.0 \mathrm{mg} / \mathrm{ml}$ protease, $1.5 \mathrm{mg} / \mathrm{ml}$ collagenase, $0.75 \mathrm{mg} / \mathrm{ml}$ hyaluronidase, and $0.05 \mathrm{mg} / \mathrm{ml}$ DNase. The cell suspension was then filtered through a $70-\mathrm{mm}$ cell strainer to remove any undigested tissue and washed two times with washing medium (RPMI 1640 supplemented with 2\% fetal calf serum, $2 \mathrm{mmol} / \mathrm{l}$ glutamine, $100 \mathrm{U} / \mathrm{ml}$ penicillin, and $100 \mathrm{mg} / \mathrm{ml}$ streptomycin). The cell pellet was resuspended in erythrocyte lysis buffer and washed with washing medium. After washing, NECs were suspended in culture medium (basal epithelial growth medium). Viability was assessed through the exclusion of trypan blue stain. The epithelial cells were confirmed by cytokeratin $8 / 18$ staining. Different concentrations of recombinant IL-31 $(1-100 \mathrm{ng} / \mathrm{ml})$ were incubated with PECs $(500 \mu \mathrm{l}$, $\left.10^{5} / \mathrm{ml}\right)$ treated with or without recombinant human IFN- $\gamma(10 \mathrm{ng} / \mathrm{ml}$; ImmunoTools, Friesoythe, Germany), IL-4, IL-17 in 48-well plate or 24 -well plate. PBS was used as negative control. After $24 \mathrm{~h}$ incubation, the supernatants were collected and analyzed.

\section{Statistical Analysis}

All data were expressed as mean \pm SD except additional note. Analysis of variance was performed and ad hoc post-test was done for multiple comparisons. The Spearman rank correlation test was used to analyze the correlation among the expression of biomarkers and clinical stage. $P<0.05$ was considered as significant difference.

\section{STATEMENT OF FINANCIAL SUPPORT}

This study was supported by State Key Clinical Department Project.

Disclosure: The authors have no conflict of interest to disclose.

\section{REFERENCES}

1. Strachan D, Sibbald B, Weiland S, et al. Worldwide variations in prevalence of symptoms of allergic rhinoconjunctivitis in children: the International Study of Asthma and Allergies in Childhood (ISAAC). Pediatr Allergy Immunol 1997;8:161-76. 
2. Ait-Khaled N, Anderson HR, Asher MI, et al. Worldwide time trends for symptoms of rhinitis and conjunctivitis: phase III of the International Study of Asthma and Allergies in Childhood. Pediatr Allergy Immunol 2007;19:110-24.

3. Hamouda S, Karila C, Connault T, Scheinmann P, de Blic J. Allergic rhinitis in children with asthma: a questionnaire-based study. Clin Exp Allergy 2008;38:761-6.

4. Bochner BS, Schleimer RP. Mast cells, basophils, and eosinophils: distinct but overlapping pathways for recruitment. Immunol Rev 2001; 179:5-15.

5. Hansen I, Klimek L, Mösges R, Hörmann K. Mediators of inflammation in the early and the late phase of allergic rhinitis. Curr Opin Allergy Clin Immunol 2004;4:159-63.

6. Ling EM, Smith T, Nguyen XD, et al. Relation of CD4+CD25+ regulatory T-cell suppression of allergen-driven T-cell activation to atopic status and expression of allergic disease. Lancet 2004;363:608-15.

7. Dillon SR, Sprecher C, Hammond A, et al. Interleukin 31, a cytokine produced by activated $\mathrm{T}$ cells, induces dermatitis in mice. Nat Immunol 2004;5:752-60.

8. Sonkoly E, Muller A, Lauerma AI, et al. IL-31: a new link between T cells and pruritus in atopic skin inflammation. J Allergy Clin Immunol 2006;117:411-7.

9. Neis MM, Peters B, Dreuw A, et al. Enhanced expression levels of IL-31 correlate with IL-4 and IL-13 in atopic and allergic contact dermatitis. J Allergy Clin Immunol 2006;118:930-7.

10. Raap U, Weißmantel S, Gehring M, Eisenberg AM, Kapp A, FölsterHolst R. IL-31 significantly correlates with disease activity and Th2 cytokine levels in children with atopic dermatitis. Pediatr Allergy Immunol 2012;23:285-8.

11. Lei Z, Liu G, Huang Q, et al. SCF and IL-31 rather than IL-17 and BAFF are potential indicators in patients with allergic asthma. Allergy 2008;63: 327-32.

12. Yu JI, Han WC, Yun KJ, Moon HB, Oh GJ, Chae SC. Identifying Polymorphisms in IL-31 and Their Association with Susceptibility to Asthma. Korean J Pathol 2012;46:162-8.

13. Shah SA, Ishinaga H, Hou B, Okano M, Takeuchi K. Effects of interleukin-31 on MUC5AC gene expression in nasal allergic inflammation. Pharmacology 2013;91:158-64.

14. Okano M, Fujiwara T, Higaki T, et al. Characterization of pollen antigeninduced IL-31 production by PBMCs in patients with allergic rhinitis. J Allergy Clin Immunol 2011;127:277-9, 279.e1-11.

15. Stott B, Lavender P, Lehmann S, Pennino D, Durham S, SchmidtWeber CB. Human IL-31 is induced by IL-4 and promotes TH2-driven inflammation. J Allergy Clin Immunol 2013;132:446-54.e5.
16. Coyle AJ, Wagner K, Bertrand C, Tsuyuki S, Bews J, Heusser C. Central role of immunoglobulin ( $\mathrm{Ig}$ ) $\mathrm{E}$ in the induction of lung eosinophil infiltration and $\mathrm{T}$ helper 2 cell cytokine production: inhibition by a nonanaphylactogenic anti-IgE antibody. J Exp Med 1996;183:1303-10.

17. Wenzel S. Severe asthma in adults. Am J Respir Crit Care Med 2005;172:149-60.

18. Baggiolini M, Walz A, Kunkel SL. Neutrophil-activating peptide-1/ interleukin 8, a novel cytokine that activates neutrophils. J Clin Invest 1989;84:1045-9.

19. Barnes PJ. The cytokine network in asthma and chronic obstructive pulmonary disease. J Clin Invest 2008;118:3546-56.

20. Gerber HP, Malik AK, Solar GP, et al. VEGF regulates haematopoietic stem cell survival by an internal autocrine loop mechanism. Nature 2002;417:954-8.

21. Ip WK, Wong CK, Li ML, Li PW, Cheung PF, Lam CW. Interleukin-31 induces cytokine and chemokine production from human bronchial epithelial cells through activation of mitogen-activated protein kinase signalling pathways: implications for the allergic response. Immunology 2007;122:532-41.

22. Gong Y, Koh DR. Neutrophils promote inflammatory angiogenesis via release of preformed VEGF in an in vivo corneal model. Cell Tissue Res 2010;339:437-48.

23. Ye P, Rodriguez FH, Kanaly S, et al. Requirement of interleukin 17 receptor signaling for lung CXC chemokine and granulocyte colony-stimulating factor expression, neutrophil recruitment, and host defense. J Exp Med 2001;194:519-27.

24. Moseley TA, Haudenschild DR, Rose L, Reddi AH. Interleukin-17 family and IL-17 receptors. Cytokine Growth Factor Rev 2003;14:155-74.

25. Schnyder-Candrian S, Togbe D, Couillin I, et al. Interleukin-17 is a negative regulator of established allergic asthma. J Exp Med 2006;203:2715-25.

26. Chen Y, Thai P, Zhao YH, Ho YS, DeSouza MM, Wu R. Stimulation of airway mucin gene expression by interleukin (IL)-17 through IL-6 paracrine/ autocrine loop. J Biol Chem 2003;278:17036-43.

27. Brozek JL, Bousquet J, Baena-Cagnani CE, et al.; Global Allergy and Asthma European Network; Grading of Recommendations Assessment, Development and Evaluation Working Group. Allergic Rhinitis and its Impact on Asthma (ARIA) guidelines: 2010 revision. J Allergy Clin Immunol 2010;126:466-76.

28. Pedersen SE, Hurd SS, Lemanske RF Jr, et al.; Global Initiative for Asthma. Global strategy for the diagnosis and management of asthma in children 5 years and younger. Pediatr Pulmonol 2011;46:1-17.

29. Kristina I, Jörgen PP, Magnus PB, Bijar G. Clara cell protein in nasal lavage fluid and nasal nitric oxide-biomarkers with anti-inflammatory properties in allergic rhinitis. Clin Mol Allergy 2012;10:4. 